\title{
Biological Trajectory for Psychosocial Risk Factors in Psychiatric Disorders- A Concept Based Review
}

\author{
Amresh Shrivastava1, James Boylan², Yves Bureau'2, Avinash De Sousa ${ }^{3}$, Nilesh Shah ${ }^{3}$ \\ ${ }^{1}$ Department of Psychiatry, University of Western Ontario, Lawson Health Research Centre, London, Canada \\ ${ }^{2}$ Department of Psychiatry, University of Western Ontario, London, Canada \\ ${ }^{3}$ Department of Psychiatry, Lokmanya Tilak Municipal Medical College, Mumbai, India \\ Email: avinashdes888@gmail.com
}

Received 19 October 2014; revised 15 November 2014; accepted 10 December 2014

Academic Editor: Serafini Gianluca, Sapienza University of Rome, Italy

Copyright (C) 2015 by authors and Scientific Research Publishing Inc.

This work is licensed under the Creative Commons Attribution International License (CC BY). http://creativecommons.org/licenses/by/4.0/

(c) (i) Open Access

\begin{abstract}
Current understanding of mental disorders is based upon "biopsychosocial model". Research also suggests what biological changes take place in a particular disorder as well as nature of risk which arises from psychological, social and environmental conditions. However it remains unclear how these psychosocial and environmental risk factors interact with biological factors which lead to clinical syndromes. This paper examines interrelationship of psychosocial and environmental risk and biological changes observed in mental disorders and tries to identify the possibility of a pathway of the psychopathology of psychiatric disorders. The review aims to demonstrate that significant advances in the fields of psychosocial, cultural, anthropological and neurobiological research provide novel insights into the etiology of mental disorders. There are neurochemical, functional and structural neurobiological, neurocognitive, immunological findings and findings from gene-environment interaction that appears promising. However these findings are in an isolated manner. Comprehensive studies examining major biological changes together in relation to psychosocial risk factors are lacking. Every individual reacts differently to the same environmental risk while there tends to be similarities in individual outcome in response to such stressors. The findings though robust independently, remain very preliminary to suggest a sequential trajectory for developing a clear pathway for pathogenesis. It is currently unclear whether there is a differential psychopathological impact of psychosocial stressors in different cultures despite the extensive variability both between and within major social groups and societies. Further research investigating modifiable and non-modifiable risk factors in context of prevailing socio-economic conditions is urgently needed to plan effective interventions.
\end{abstract}




\title{
Keywords
}

\author{
Psychosocial Stress, Resilience, Social Cognition, Epigenetics, Neurobiology, Psychosocial Risk \\ Factors
}

\section{Introduction}

Psychosocial stressors can trigger or exacerbate conditions such as schizophrenia, depression, anxiety and other psychiatric conditions. A supportive environment is protective against developing or exacerbating mental health problems just as a stressful environment appears to increase vulnerability to mental illness [1]. The extent to which biological-environmental interaction is necessary for the development of psychopathology is currently unclear. However, emerging research suggests that neither category of risk factors can be adequately understood in isolation [2] [3]. Research advances have repeatedly confirmed that in the biochemical pathway for psychosocial risk factors, the main focus is the hypothalamo-pituitary-adrenal (HPA) axis and thus the HPA-axis changes may be a representative of the biological effect of psychosocial risk factors [4].

\section{Environmental Factors and Stress}

Environmental stressors can have catastrophic consequences for mental and physical health. Potentially harmful biological adaptation to negative experiences appears to be inevitable with extreme or prolonged stress. For example, stress can cause significant alterations to the HPA axis which can serve to increase susceptibility to subsequent environmental stressors [5]. Acute stress increases cortisol secretion, which may produce short-term reversible damage in the hippocampus. Repeated stress causes the atrophy of dendrites of pyramidal neurons in the hippocampus through a mechanism involving both glucocorticoids and the excitatory amino acid neurotransmitters released during and after stress. This atrophy is reversible if the stress is short-lived, but stress lasting for months can severely damage hippocampal neurons [6].

\section{Environment Stress Interaction Using Post Traumatic Stress Disorder (PTSD) as a Model}

PTSD is a classic example how risk factors like trauma affect biological functions which includes neurochemical, endocrinal, neurobiological and cognitive one. In PTSD, a perception of threat from internal or external stimuli signals an alarm in the amygdala, which results in a surge of norepinephrine. A part of the brain called the cingulate gyrus determines whether the threat is real or imagined, and cognitive appraisal occurs as the neocortex provides logical analysis. In the case of trauma, these processes lead to sustained autonomic arousal and recur-ring intrusive cognitions [6]. PTSD results from a fear-conditioning process in individuals with an exaggerated susceptive-ability to stress. Chronic PTSD may involve progressive deterioration of function within the brain [7]. A proposed neuro-circuit model of PTSD shows the functional relationships among three brain structures i.e. the prefrontal cortex, the amygdala, and the hippocampus. The prefrontal cortex of the brain is important for attention, emotional regulation, and conditioned fear, and normally attends to current environmental cues, inhibiting irrelevant or distracting sensory input. The amygdala assigns meaning to incoming sensory information by connecting union targeted memory images with associated emotional experiences, and is also part of fear conditioning. In PTSD, hyper-responsiveness of the amygdala to threat-related stimuli results in symptoms of hyperarousal [8].

\section{Resilience and Psychopathology}

Resilience is the capacity and dynamic process of adaptively overcoming stress and adversity. Every individual experiences stressful events and the majority are exposed to trauma at some point during their life. An understanding of resilience and how it leads to good or maladaptive coping and stress response in psychiatric illnesses such as depression and posttraumatic stress disorder (PTSD) will help us understand biological and environmental interactions better [8] [9]. The understanding of resilience is overall still at an early stage and recent investigations have identified mechanisms encompassing genetic, epigenetic, developmental, psychological, and neurochemical factors that underlie the development and enhancement of resilience and factors that predict vulnera- 
bility to stress and susceptibility to psychiatric disorders in the face of stress and trauma [10]. Psychosocial risk factors are major stresses which give rise to complex neurobehavioral changes, these can be pathological, while effective treatment for dealing with risk factors do revert some of these changes. Resilience perhaps plays an important part and leads to a neurobehavioral adaptive mechanism. Thus, it is likely that manifestations of psychiatric syndromes are related to a complex way with neuroplasticity, adaptation and behavioral changes [11].

Our understanding of psychosocial risk factors has been changing in recent years. Similar forms of social determinants of mental illness appear to be characteristics of people who have received a psychiatric diagnosis across all countries and socio-economic backgrounds. Psychosocial risk can be defined as those fundamental etiopathological factors known to have a causal or correlational association to mental illness. The relationship between psychosocial stress and mental illness is complex. The experience of major psychosocial risk factors (such as poverty, traumatic stress or abuse) can be sufficient in itself to trigger mental illness. However, most people are resilient and are typically able to persevere against major life stressors. On average, even amongst those who successfully cope with psychosocial risk factors, the experience of such psychosocial stressors appears to reduce people's resilience against subsequent negative life events [12].

\section{Social Determinants of Mental Illness}

Although it is beyond the scope of this review to mention all possible psychosocial risk factors, we will discuss the most important risk factors in predicting mental disorder. Age, gender, recent migration and socioeconomic status appear to be important psychosocial risk factors [13]. In another study, the five most frequently reported psychosocial risk factors for mental illness were problems in family functioning, financial hardship, relationship issues, mental illness and loneliness [14]. Socio-economic conditions are associated with mental disorder in both the developing and the developed world [15]. Psychosocial stress is a significant risk factor for both physical and mental disorder and internationally, the strongest social predictors of general health are the social gradient of a society, emotional stress, pregnancy circumstances and early life experiences, social exclusion, workplace dissatisfaction, unemployment, positive social support, addictions, nutrition, and effective available public transportation. Also noteworthy is that social risk factors make subsequent negative social experiences more likely. For example, poor social support may lead to addiction which reduces employment opportunities and socioeconomic status, etc. [16]. At every step in the social determinants of mental illness there is an intertwining of neurobiology that plays a role in the course and prognosis of the disease as well as factors that determine its onset [17].

\subsection{Social Support and Mental Health}

Social interconnectivity, positive support and family structure are important to the promotion of mental health and resilience. People who receive social and emotional support from others are more likely to sustain and overcome social and economic challenges. Negative psychosocial consequences of failure in interpersonal relationships have been well demonstrated. Loneliness, marital and relationship stress, domestic violence, partner violence, and stress due to educational or professional examination are all major social factors which can contribute to mental disorder [18]. Several lines of research have illustrated that negative environments can precipitate psychopathology, particularly in the context of relatively increased biological risk, while social resources can buffer the effects of these environments. The social hormone oxytocin has been implicated in the same along with the individual variability in oxytocin responses [19]. It has been reported that the expression of trait anxiety as a function of threat-related amygdala reactivity is moderated by perceived social support, a resource for coping with adversity. A significant positive correlation between amygdala reactivity and trait anxiety is evident in individuals reporting below-average levels of support but not in those reporting average or above-average levels. These results were consistent across multiple measures of trait anxiety and were specific to anxiety in that they did not extend to measures of broad negative or positive affect. Research findings illuminate a biological pathway, namely moderation of amygdala-related anxiety, through which social support may confer resilience to psychopathology. Thus the links between neural reactivity and behavior are not static but rather may be contingent on social resources [20].

\subsection{Socioeconomic Status and Poverty}

Globally, people in lower socioeconomic strata have twice the incidence of serious illness compared to people in 
the higher socioeconomic strata [21]. Low socio-economic status is highly associated with stress and the experience of symptoms associated with mental illness such as anxiety, low self-esteem, social isolation and general lack of control over work and home life [22]. Psychosocial risk and biological vulnerability associated with low socioeconomic status tends to accumulate across people's lifespan further increasing the probability of mental illness [23]. Meaningful employment, which provides job security, is important to subjective well being and life satisfaction. Underprivileged social groups, those who are unemployed, homeless, ethnic minorities, the disabled, refugees are at particular risk of impoverished employment and psychosocial experience [24]. An increased rate of schizophrenia and other mental disorders has been reported in migrant population and presently immigrants of South East Asia have been a focus of several specialized intervention programs [25]. Inequalities in society are associated with poor health outcomes and greater risk of premature death. For example, unemployment is a leading worldwide cause of suicidal behavior. Studies suggest that individual health suffers when people lack opportunity to use their skills and have low decision-making authority [26]. With regard to poverty and social disadvantage, particular areas of interest are the stress sensitization consequences stemming from exposure to adversity over the life course. Contemporary stress sensitization theory provides important clinical utility in articulating mechanisms through which these multiple levels exert influence on mental health. Stress sensitization models extend understanding of neurobiological and functional contexts within which extreme stressors operate and make clear how these can influence psychologically traumatic outcomes [27]. Childhood neglect, childhood family poverty, and childhood neighborhood poverty each contribute to poor outcomes later in life. While interventions should be developed for neglected children to prevent negative outcomes, the current findings suggest that it is also important to consider the ecological, neurobiological and genetic context in which these children are growing up [28].

\subsection{Addiction}

Addiction is another salient socially associated risk factor. It is associated with social breakdown and frequently works to increase social inequality. It places a severe burden on an individual's ability to maintain intimate social relationships and is associated with a variety of other social risk factors discussed in this review, such as malnutrition, social harassment, examination stress, and it can be a risk factor for suicidal behavior [29]. Recent concepts in addiction explain these disorders as an interface between three neurobiological systems viz. an impulsive amygdala striatum system that provides for automatic and habitual salient behaviours, the prefrontal cortex which is involved in decision making and rationale and the insula which is involved interoception states into conscious states and decision making processes involved in uncertain risk and reward [30]. The neuroimmune system (i.e., the immune system and those components of the nervous system that help regulate immune responses), and in particular the innate immune system, play a role in the development of addictions, including alcoholism and cannabis use, particularly in the context of stressful situations. Certain cells of the neuroimmune system are activated both by stress and by environmental factors such as alcohol and cannabis consumption, resulting in the induction of genes involved in innate immunity. One of the molecules mediating this gene induction is a regulatory protein called nuclear factor-KB, which activates many innate immune genes. Innate immune gene induction in certain brain regions (e.g., the frontal cortex), in turn, can disrupt decision making, which is a characteristic of addiction to alcohol and other drugs. Likewise, altered neuroimmune signaling processes are linked to alcohol-induced negative affect and depression-like behaviors and also regulate alcohol-drinking behavior [31] [32].

\subsection{Malnutrition}

Malnutrition, in terms of both undernourishment and obesity, grossly affects both physical and mental health [33]. On the other hand, eating to excess and limited opportunity for exercise in modern daily life has led to an epidemic of obesity which is associated with social stigma, self-esteem issues, and lifelong health complications [34]. In either case, malnutrition has the potential to both create and exacerbate psychosocial risk and biological vulnerability. Undernutrition still affects mothers and children in developing countries and thus remains the major focus of nutritional intervention efforts. Neuronal development, which classically includes neurogenesis, migration, maturation, and synapse refinement, begins in utero and continues into the early postnatal period. These processes are not only genetically regulated but also clearly susceptible to environmental manipulation. Dietary deprivation during early life is known to have adverse effects on brain anatomy, physiology, and biochemistry, 
and may even lead to permanent brain damage. Although all nutrients are important for the structural development of the central nervous system, lipids such as long-chain polyunsaturated fatty acids, especially docosahexaenoic acid and arachidonic acid, are important for normal brain development. Deficiencies of any kind in this area predispose one to mental illness in later life [35].

\subsection{Childhood Experiences and Abuse}

Childhood social and environmental experiences are powerful predictors of adult mental health and life trajectory. Impoverished social and biological development in early childhood is associated with diminished cognitive, emotional and physical health in adulthood [36]. Psychosocial risk factors (such as social exclusion, resentment, poverty or discrimination) which can impede growth may become embedded into an individual's neurobiology. Although the exact causal mechanisms of this process are not fully understood, early life adversity appears to snowball into lifelong biological vulnerability to psychosocial stressors. Research investigating the impact of early traumatic life experience has traditionally focused on the effect of childhood abuse (physical and sexual), childhood neglect (lack of shelter, nutrition, or emotional support), parental loss early in childhood and how such early traumatic life experience is associated with the development of mental illness [37]. On similar lines, even passive exposure to domestic violence in childhood may increase susceptibility to adult psychiatric disorders [38].

Atypical social-cognitive development has been posited as a possible mechanism by which traumatic childhood experiences, such as CSA, impede normative developmental processes. For example, CSA may lead to the development of aggressive behavior during adolescence limiting the infant's access to positive supportive relationships throughout childhood. Indeed, children who have been maltreated tend to display negatively biased social-cognitive processing styles, which may in turn increase their likelihood of reacting aggressively in ambiguous social situations [39]. CSA is also known to have neurobiological consequences. Past research has demonstrated that CSA is associated with significant dysfunction in neuroendocrine, neurotransmission and functions in the HPA axis [40] [41].

\section{Biological Vulnerability and Mental Disorder}

Social stressors are strongly associated with neurological changes in the brain. Recent provocative evidence suggests that these changes are mediated by changes in genetic expression. Early life stressors are associated with changes in HPA-axis functioning and promotes changes in brain morphology similar to what is seen in adults with depression [42]. For example, sensory deprived children have significantly reduced brain volume, especially in temporal regions associated with emotion regulation. However, subsequent evidence suggests that the long term effects of childhood stress can be moderated by protective genetic mechanisms and can be prevented, or potentially reduced by psychological and pharmacological intervention [43].

The development of psychiatric disorder due to psychosocial stress is a complex neurobiological process, unfolding according to changes in gene-environment expression, neuroanatomical neurocognitive, and neurochemical factors. There is strong evidence for an association between psychosocial risk factors and changes in neurobiological function; however, our understanding of the critical processes and the trajectory of this association across time is not well understood. Current theories, such as the biopsychosocial model [44], host-vector theory [45] and stress-diathesis models [46] provide convincing explanations for the relationship between psychosocial risk and mental disorder. Generally speaking, these models predict that multiple causes can lead to similar outcomes (such as depression), and that similar causal factors can give rise to multiple effects (such as hyperlipidemia or nutritional deficiency). Risk factors appear to either precipitate pre-existing abnormalities or cause neurobiological changes responsible for symptom development [47].

We propose the following explanations for these findings which most likely would work collectively but may be mutually exclusive. It may also argue that the three possibilities form logical components in the pathways for pathogenesis:

1) Psychosocial stressors may have a causal role in modulating gene-expression which consequently causes changes in neurobiological function. According to this perspective, variability in symptom endorsement and severity in mental disorder can be seen as a consequence of unique genetic origin and lifetime gene-environment interaction.

2) Psychosocial stressors lead to a deterioration of biological protective mechanisms increasing the possibility 
that latent psychopathology may be "unmasked". According to this perspective, the form and extent of deterioration of protective mechanisms would determine symptom endorsement and severity.

3) Psychosocial stressors may have an independent causal role in neurobiological changes, limiting individual responsiveness to subsequent stressors and increasing the likelihood of psychiatric symptoms.

\subsection{Neuroanatomical Changes}

Structural and functional neuroanatomical changes are well documented in psychiatric disorders such as schizophrenia, mood disorders, PTSD, OCD and related disorders. Neuroanatomical changes are frequently demonstrated in prefrontal brain regions mid brain, and subcortical regions. For example, studies of patients who are at-risk for the development of psychosis suggest that the neurobiological changes observed in imaging studies appear to precede the full onset of mental illness [48] [49]. Past research also suggests that psychosocial stress may be associated with changes in structural and functional neuroanatomical changes independently of mental disorder [50] [51]. For example, a study of flight attendants working long international shifts found significant reductions in brain volume, particularly in areas associated with memory and emotional control associated with long and stressful time zone crossing shift work. It is worth noting that after a sufficient rest period, brain morphology and volume returned to previous normal ranges [51]. It is, however, often difficult to experimentally investigate the possibility that the relationship between psychopathology and neuroanatomical changes is mediated by the presence of psychosocial risk factors.

\subsection{Social Cognition}

Social cognitive research involves the study of how people encode, store, process and retrieve social information and apply it to social situations. Social skill is an important predictor of people's ability to obtain social support, socio-economic success, and resilience against stressors [52]. There has been considerable recent interest in the investigation of the neurological correlates of social cognition. For example, neuropsychological studies have demonstrated that brain injury (particularly to the frontal lobes) can adversely affect social decision making [53] [54]. Likewise, people diagnosed with certain mental illnesses are also known to show differences in how they process social information. For example, people with major depressive disorder have more negative ideation and anticipations of failure in social interactions [55].

Some aspects of social cognition (such as face recognition) appear to be innate [56]. For example, interventions which target negative biases in social-cognitive processing have been demonstrably effective in reducing anti-social or aggressive behaviors. On the other hand environmental opportunity is a powerful predictor of life success. Past research has found a significant correlation between overall cognitive ability and individual differences in brain size, age, sex, social class, and ethnic background. The relationship between social cognitive ability and environmental opportunity (or psychosocial stressors) is bi-directional. Socioeconomic background is associated with superior cognitive functioning. Advanced cognitive ability is a strong predictor of one's ability to climb socio-economic ladders providing further opportunities for positive social feedback. Thus, there appears to be a paradoxical relationship between socioeconomic factors and cognitive status: poor social cognitive status can contribute to psychosocial and biological vulnerability, which can then serve to further deteriorate supportive social resources [57].

\subsection{Neurocognition}

Neurocognitive dysfunction is frequently reported amongst individuals diagnosed with major mental disorders such as schizophrenia, depression, anxiety, obsessive compulsive disorder and post-traumatic stress disorder [58]. Dysfunctional thought patterns can serve as a sufficient foundation in the etiology of mental disorder, just as treating disordered thought patterns can serve as an effective and enduring intervention through cognitivebehavioral treatment [59].

Cognitive dysfunction can also be viewed as a general form of vulnerability: it is typical amongst at-risk individuals and is highly heritable amongst first-degree relatives [60]. Changes in cognitive functioning have been correlated with personality traits, perceptions of the environment, and stress responsiveness. Moreover, cognitive dysfunction has been correlated with neurological changes in recent imaging studies of both patients and in asymptomatic relatives [61]. A detailed discussion of the cognitive neuroscience of psychosocial risk and mental 
disorder is out of the scope for this review; however, there appears to be a complex and multi-directional relationship between thought processes, such as decision making, and neuroanatomical functioning which is highly susceptible to interference from psychosocial stress factors [62].

\subsection{The Role of Nor-Epinephrine}

Evidence suggests that the experience of intense stress can also serve to increase the sensitivity to subsequent experiences of stress through an increase in ACTH levels, increased pituitary volume, changes in hippocampal volume, and overall hyperactivity in the HPA axis [63]. Biochemical changes in response to early life stress are reliably associated with changes in the HPA Axis leading to cortisol and adrenocorticotropic hormone (ACTH) changes [64]. Under stressful conditions, cortisol levels increase, leading to chain of events that ultimately provide immediate energy that keeps individuals alert via stimulation of the adrenergic system [65]. Early traumatic experience appears to significantly change norepinephrine sensitivity; creating nor-epinephrine (NE) system hypersensitivity and potentially reducing the protective neurochemical responses to stress. Similar patterns of general disturbances in early brain development are implicated in the development of several psychiatric disorders, such as autism, schizophrenia, and mental retardation. Disruptive prenatal stress postnatal trauma or complications can further increase this risk [66]. Experimental studies have demonstrated that immune reactions to stress in middle and late gestation periods in mice are "dissociable in terms of fetal brain cytokine responses to maternal inflammation causing pathological consequences in brain and behavior" [67]. Middle and late gestation periods correspond to two windows with differing vulnerability to adult behavioral dysfunction leading to acute cytokine responses in the fetal brain and brain neuropathology in early adolescence [68].

\subsection{The Role of the Hippocampus}

The hippocampus has long been investigated as a central component of systems responsible for neurological patterns of adaptation to stress and hippocampal structures appear to play a critical role in mood regulation [69]. Clinical studies demonstrate that a reduction in hippocampal volume in response to childhood abuse. Evidence suggests that the hippocampus appears to release neurotoxins in response to early childhood traumatic experiences, accounting for subsequent atypical morphological and functional anomalies [70]. The discovery of corticotrophin-releasing factor (CRF), which is secreted by the hippocampus, has significantly contributed to our understanding of neurochemical response mechanisms in the human brain. Increased cortisol level, CRF and corticotrophin releasing hormone are consistent findings in both acute stress and accumulated stress. CRF is heterogeneously distributed in CNS in cerebral cortex, central nucleus of amygdala, and the brain stem [71].

\section{Epigenetics}

Single genetic factors consistently failed to predict phenotype expression, however, numerous polymorphisms have been shown to moderate the effect of environmental adversity on the development of depression and treatment response. Current evidence from studies of gene-environment interaction is unable to distinguish between major psychiatric conditions; however, this research has demonstrated atypical patterns of expression of transporter genes associated with abnormalities in dopamine, serotonin norepinephrine as well as MAO levels in the brain [72]. Research indicates that nature and nurture actively interact throughout the lifespan and play an important role in the genesis of psychopathology. There is growing focus on study the etiology of mental disorder according to "endophenotypic" expression of traits [73]. An endophenotype can be conceptualized as an intermediate stage between genotypic and phenotypic causes for normal and abnormal patterns of mental function. The study of etiology from this endophenotypical perspective has considerable promise in advancing our understanding of psychosocial risk and biological vulnerability [74].

A change in gene programming by chromatin can enhance or silence a gene-expression resulting in interindividual phenotypic differences. In addition, chromatin alterations appear to play an epigenetic role through gene marking, modification, DNA methylation and noncoding RNA. Although changes in genetic expression in response to environmental stressors appears to be stable and long lasting, this epigenetic programming also appears to be responsive and potentially reversible [75]. New data from behavioral studies has shed new light on the relationship between the social environment and epigenetic programming. The relationship between behavior and the epigenome is bidirectional: behavior can resist changes in epigenetic programming and epigenetic 
programming can resist changes in behaviour. The examination of behavioral factors have thus emergence as an important principle of analyses of the epigenome [76].

Changes in gene expression through such epigenetic mechanisms appears to be powerful and lifelong (appearing just after birth and throughout an individual's lifespan) biological mechanism supporting adaptability of the human genome. Such powerful adaption at a genetic level helps us account for variability in symptom expression and evidence of neurological changes in response to psychosocial stress. Environmental toxins, for example, may have a long-term influence on behavior through epigenetic reprogramming mechanisms. As far as phenotype consequences are concerned, unwanted epigenetic aberrations may actually be as equally as harmful as genetic damage [77].

The investigation of gene-environment interactions has gained considerable momentum in psychiatric research. Subsequent research should focus on the development of animal models to study environmental exposure, studies comparing human distinct genotype groups in terms of their responses to experimentally controlled environmental stimuli, neuroimaging measurements of changes in neuroanatomy in response to environmental stimuli, and further characterization of epigenetic influences on individual resilience factors [78] [79]. A lot of gene environment interactions and factors have been demonstrated in investigative studies into the causative nature of psychological problems in India as well [80] [81].

\section{Current Challenges}

Ongoing research seeking to further examine the etiology of mental illness is currently faced with a number of challenges viz.

1) There is considerable variability in terms of epidemiological, cultural and endophenotypic experiences of psychosocial risk factors which make them difficult to study in group analysis.

2) Specific biochemical and therapeutic probes are currently not available.

3) We currently lack sophisticated experimental tools and techniques capable of quantifiably measuring the severity and specificity of risk factor such as traumatic stress, maltreatment or abuse.

\section{Conclusions}

Psychosocial risk factors are powerful predictors of psychiatric disorders. Significant advances in the fields of psychosocial, cultural, anthropological and neurobiological research have provided novel insights into the etiology of psychiatric disorders and have suggested novel interventions in response to growing epidemiological challenges. Every individual reacts differently to the same environmental risk. However, it is also evident that there tends to be similarities in individual outcome in response to such stressors. It is currently unclear whether there is a differential psychopathological impact of psychosocial stressors in different cultures despite the extensive variability both between and within major social groups and societies. Further research investigating modifiable and non-modifiable risk factors in context of prevailing socio-economic conditions is urgently needed to plan effective interventions.

However, for a plan to be effective it is essential to have a proposed pathway of adverse life events. We propose that it is important to consider every part of the process toward pathology. By detecting the process to pathology as early as possible it should be possible to intervene at a crucial component of the process. This would mean that in order to best serve those at risk of pathology it would be necessary to moderate environment, pharmacology, and perhaps even gene expression. Our model takes into account the impact of environment at various parts of a person's life on biological systems. Not everyone is adversely susceptible to stressful situations. For those who are, there may be serious alterations to the HPA axis in that there may be a hypersensitivity to cortisol resulting in an exaggerated stress response which cascades to changes in other brain areas such as the frontal lobes impeding in judgment and cognition, and the hippocampus leading to memory problems and disinhibition of the HPA axis which then perpetuates even further the stress response. Even though many recover from this insidious mechanism, those same individuals are left vulnerable due to permanent changes and difficult environments.

Life events impact everyone's lives. While most react to these events by adapting and overcoming situations, others due to vulnerabilities are adversely influenced requiring professional interventions. Identifying a pathological process at the right time and administering the correct psychological or/and pharmacological treatment at the right time would be ideal. This review covered the major psychosocial issues that reciprocally connected to 
biological systems. The model proposed can conceivably lead to research which will maximize results from treatment.

\section{References}

[1] Bradshaw, C.P. and Garbarino, J. (2004) Social Cognition as a Mediator of the Influence of Family and Community Violence on Adolescent Development: Implications for Intervention. Annals of the New York Academy of Science, 1036, 85-105. http://dx.doi.org/10.1196/annals.1330.005

[2] Knafo, A. and Jaffee, S.R. (2013) Gene-Environment Correlation in Developmental Psychopathology. Development and Psychopathology, 25, 1-6. http://dx.doi.org/10.1017/S0954579412000855

[3] Patel, V. (2005) Social Origins, Biological Treatments: The Public Health Implications of Common Mental Health Disorders. Indian Journal of Psychiatry, 47, 15-20. http://dx.doi.org/10.4103/0019-5545.46068

[4] Borges, S., Gayer-Anderson, C. and Mondelli, V. (2013) A Systematic Review of the Activity of the HypothalamoPituitary-Adrenal Axis in First Episode Psychosis. Psychoneuroendocrinology, 38, 603-611. http://dx.doi.org/10.1016/j.psyneuen.2012.12.025

[5] Radley, J.J., Kabbaj, M., Jacaobson, L., Heydendael, W., Yehuda, R. and Herman, J.P. (2011) Stress Risk Factors and Stress Related Pathology: Neuroplasticity, Epigenetics and Endophenotypes. Stress, 14, 481-497. http://dx.doi.org/10.3109/10253890.2011.604751

[6] Vogt, B. (2005) Pain and Emotion Interactions in the Subregions of the Cingulate Gyrus. Nature Review Neuroscience, 6, 533-544. http://dx.doi.org/10.1038/nrn1704

[7] McEwen, B.S. (2007) Physiology and Neurobiology of Stress and Adaptation: The Central Role of the Brain. Physiology Review, 87, 873-904. http://dx.doi.org/10.1152/physrev.00041.2006

[8] Kim, M.J., Loucks, R.A., Palmer, A.L., Brown, A.C., Solomon, K.M., Marchante, A.N. and Whalen, P.J. (2011) The Structural and Functional Connectivity of the Amygdala: From Normal Emotion to Pathological Anxiety. Behaviour and Brain Research, 223, 403-410. http://dx.doi.org/10.1016/j.bbr.2011.04.025

[9] Shastri, P.C. (2013) Resilience: Building Immunity in Psychiatry. Indian Journal of Psychiatry, 55, 224-234. http://dx.doi.org/10.4103/0019-5545.117134

[10] Olszewski, T.M. and Varrasse, J.F. (2005) The Neurobiology of PTSD: Implications for Nurses. Journal of Psychosocial Nursing and Mental Health Services, 43, 40-47.

[11] Rutter, M. (2012) Annual Research Review: Resilience and Its Clinical Implications. Journal of Child Psychology and Psychiatry, 54, 474-487. http://dx.doi.org/10.1111/j.1469-7610.2012.02615.x

[12] Feder, W.A., Cohen, H., Kim, J.J., Calderon, S., Charney, D.S. and Mathe, A.A. (2013) Understanding Resilience. Frontiers in Behavioral Neuroscience, 7, 10-19.

[13] Karatsoreos, I.N. and McEwen, B.S. (2013) The Neurology and Physiology of Resilience and Adaptation across the Life Course. Journal of Child Psychology and Psychiatry, 54, 337-347. http://dx.doi.org/10.1111/jcpp.12054

[14] Karatsoreos, I.N. and McEwen, B.S. (2011) Psychobiological Allostasis: Resistance, Resilience and Vulnerability. Trends in Cognitive Science, 15, 576-584. http://dx.doi.org/10.1016/j.tics.2011.10.005

[15] Vijaykumar, L. (2010) Indian Research on Suicide. Indian Journal of Psychiatry, 52, 291-296. http://dx.doi.org/10.4103/0019-5545.69255

[16] Shrivastava, A.K., Johnston, M.E., Stitt, L., Thakar, M., Sakel, G., Iyer, S., Shah, N. and Bureau, Y. (2012) Reducing Treatment Delay for Early Intervention: Evaluation of a Community Based Crisis Helpline. Annals of General Psychiatry, 11, 11-20. http://dx.doi.org/10.1186/1744-859X-11-20

[17] Rutten, B.P.F., Hammels, C., Geschwind, N., Menne-Lothmann, C., Pishva, E., Schruers, K. and Wichers, M. (2013) Resilience in Mental Health: Linking Psychological and Neurobiological Perspectives. Acta Psychiatrica Scandanavica, 128, 3-20. http://dx.doi.org/10.1111/acps.12095

[18] Reiss, F. (2013) Socio-Economic Inequalities and Mental Health Problems in Children and Adolescents: A Systematic Review. Social Science and Medicine, 90, 24-31. http://dx.doi.org/10.1016/j.socscimed.2013.04.026

[19] Kumsta, R. and Heinrichs, M. (2013) Oxytocin, Stress and Social Behavior: Neurogenetics of the Human Oxytocin System. Current Opinion in Neurobiology, 23, 11-16. http://dx.doi.org/10.1016/j.conb.2012.09.004

[20] Hyde, L.W., Gorka, A., Manuck, S.B. and Hariri, A.R. (2011) Perceived Social Support Moderates the Link between Threat-Related Amygdala Reactivity and Trait Anxiety. Neuropsychologia, 49, 651-656. http://dx.doi.org/10.1016/j.neuropsychologia.2010.08.025

[21] Lim, C., Chong, S.A. and Keefe, R. (2009) Psychosocial Factors in the Neurobiology of Schizophrenia: A Selective Review. Annals of the Academy of Medicine Singapore, 38, 402-406. 
[22] Fisher, M.P. and Elnitsky, C. (2012) Health and Social Services Integration: A Review of Concepts and Models. Social Work and Public Health, 27, 441-468. http://dx.doi.org/10.1080/19371918.2010.525149

[23] Roberts, B. and Browne, J. (2011) A Systematic Review of Factors Influencing the Psychological Health of Conflict Affected Populations in Low and Middle Income Countries. Global Public Health, 6, 814-829. http://dx.doi.org/10.1080/17441692.2010.511625

[24] Matthews, K.A. and Gallo, L.C. (2011) Psychological Perspectives on Pathways Linking Socioeconomic Status and Physical Health. Annual Review of Psychology, 62, 501-530. http://dx.doi.org/10.1146/annurev.psych.031809.130711

[25] Bhugra, D. (2004) Migration and Mental Health. Acta Psychiatrica Scandanavica, 109, 243-258. http://dx.doi.org/10.1046/j.0001-690X.2003.00246.x

[26] Liz, Z., Page, A., Martin, G. and Taylor, R. (2011) Attributable Risk of Psychiatric and Socioeconomic Factors for Suicide from Individual Level Population Based Studies: A Systematic Review. Social Science and Medicine, 72, 608616. http://dx.doi.org/10.1016/j.socscimed.2010.11.008

[27] Nurius, P.S., Uehara, E. and Zatzick, D.F. (2013) Intersection of Stress, Social Disadvantage, and Life Course Processes: Reframing Trauma and Mental Health. American Journal of Psychiatric Rehabilitation, 16, 91-114. http://dx.doi.org/10.1080/15487768.2013.789688

[28] Nikulina, V., Widom, C.S. and Czaja, S. (2011) The Role of Childhood Neglect and Childhood Poverty in Predicting Mental Health, Academic Achievement and Crime in Adulthood. American Journal of Community Psychology, 48, 309-321. http://dx.doi.org/10.1007/s10464-010-9385-y

[29] Wong, C.C., Mill, J. and Fernandes, C. (2011) Drugs and Addiction: An Introduction to Epigenetics. Addiction, 106, 480-489. http://dx.doi.org/10.1111/j.1360-0443.2010.03321.x

[30] Noël, X., Brevers, D. and Bechara, A. (2013) A Neurocognitive Approach to Understanding the Neurobiology of Addiction. Current Opinion in Neurobiology, 23, 632-638. http://dx.doi.org/10.1016/j.conb.2013.01.018

[31] Crews, F.T. (2012) Immune Function Genes, Genetics, and the Neurobiology of Addiction. Alcohol Research and Current Reviews, 34, 355-361.

[32] Shrivastava, A., Johnston, M. and Tsuang, M. (2011) Cannabis Use and Cognitive Dysfunction. Indian Journal of Psychiatry, 53, 187-191. http://dx.doi.org/10.4103/0019-5545.86796

[33] Weaver, L.J. and Headley, C. (2009) Moving beyond Hunger and Nutrition: A Systematic Review of the Evidence Linking Food Insecurity and Mental Health in Developing Countries. Ecology, Food and Nutrition, 48, 263-284. http://dx.doi.org/10.1080/03670240903001167

[34] Karasu, S.R. (2013) Psychotherapy-Lite: Obesity and the Role of the Mental Health Practitioner. American Journal of Psychotherapy, 67, 3-22.

[35] de Souza, A.S., Fernandes, F.S. and Tavares do Carmo, M.D.G. (2011) Effects of Maternal Malnutrition and Postnatal Nutritional Rehabilitation on Brain Fatty Acids, Learning, and Memory. Nutrition Review, 69, 132-144. http://dx.doi.org/10.1111/j.1753-4887.2011.00374.x

[36] McLaughlin, K.A., Green, J.G., Gruber, M.J., Sampson, N.A., Zaslavsky, A.M. and Kessler, R.C. (2010) Childhood Adversities and Adult Psychiatric Disorders in the National Comorbidity Survey Replication II: Association and Persistence of DSM-IV Disorders. Archives of General Psychiatry, 67, 124-132. http://dx.doi.org/10.1001/archgenpsychiatry.2009.187

[37] Gould, F., Clarke, J., Heim, C., Harvey, P.D., Majer, M. and Nemeroff, C.B. (2012) The Effects of Child Abuse and Neglect on Cognitive Functioning in Adulthood. Journal of Psychiatric Research, 46, 500-506. http://dx.doi.org/10.1016/j.jpsychires.2012.01.005

[38] Varghese, S., Prasad, J.H. and Jacob, K.S. (2013) Domestic Violence as a Risk Factor for Infant and Child Mortality: A Community-Based Case-Control Study from Southern India. National Medical Journal of India, 26, 142-146.

[39] Norman, R.E., Byambaa, M., De, R., Butchart, A., Scott, J. and Vos, T. (2012) The Long Term Health Consequences of Child Physical Abuse, Emotional Abuse and Neglect: A Systematic Review and Meta-Analysis. PLoS Medicine, 9, e1001349. http://dx.doi.org/10.1371/journal.pmed.1001349

[40] McCrory, E., De Brito, S.A. and Viding, E. (2012) The Link between Child Abuse and Psychopathology: A Review of Neurobiological and Genetic Research. Journal of the Royal Society of Medicine, 105, 151-156. http://dx.doi.org/10.1258/jrsm.2011.110222

[41] Prakash, O. and Rao, T.S.S. (2010) Sexuality Research in India: An Update. Indian Journal of Psychiatry, 52, $260-263$. http://dx.doi.org/10.4103/0019-5545.69243

[42] Papachristou, E., Frangou, S. and Reichenberg, A. (2012) Expanding Conceptual Frameworks: Life Course Risk Modelling for Mental Disorders. Psychiatry Research, 12, 545-549.

[43] Keshavan, M.S., Shrivastava, A. and Gangadhar, B.N. (2010) Early Interventions in Psychotic Disorders: Challenges 
and Relevance in the Indian Context. Indian Journal of Psychiatry, 52, 153-158.

http://dx.doi.org/10.4103/0019-5545.69228

[44] Engel, G.L. (1977) The Need for a New Medical Model: A Challenge for Biomedicine. Science, 196, 129-136. http://dx.doi.org/10.1126/science.847460

[45] Cassell, J. (1974) Psychosocial Processes and Stress: Theoretical Formulation. International Journal of Health Services, 4, 471-482. http://dx.doi.org/10.2190/WF7X-Y1L0-BFKH-9QU2

[46] Monroe, S.M. and Simons, A.D. (1991) Diathesis-Stress Theories in the Context of Life Stress Research: Implications for Depressive Disorders. Psychological Bulletin, 110, 406-425. http://dx.doi.org/10.1037/0033-2909.110.3.406

[47] Belsky, J. and Pluess, M. (1998) Beyond Diathesis Stress: Differential Susceptibility to Environmental Influences. Psychological Bulletin, 135, 885-908. http://dx.doi.org/10.1037/a0017376

[48] Keshavan, M.S., Tandon, R., Boutros, N.N. and Nasrallah, H.A. (2008) Schizophrenia “Just the Facts”: What We Know in 2008 Part 3: Neurobiology. Schizophrenia Research, 106, 89-107. http://dx.doi.org/10.1016/j.schres.2008.07.020

[49] Shrivastava, A. (2010) Prodromal Research: Public Health Initiatives for the Prevention of Schizophrenia. Indian Journal of Psychiatry, 52, 13-16. http://dx.doi.org/10.4103/0019-5545.58889

[50] Markham, J.A. and Koenig, J.I. (2011) Prenatal Stress: Role in Psychotic and Depressive Diseases. Psychopharmacology (Berlin), 214, 89-106. http://dx.doi.org/10.1007/s00213-010-2035-0

[51] Cho, K. (2001) Chronic Jet Lag Produces Temporal Lobe Atrophy and Spatial Cognitive Deficits. Nature Neuroscience, 4, 567-568. http://dx.doi.org/10.1038/88384

[52] Mar, R.A. (2011) The Neural Bases of Social Cognition and Story Comprehension. Annual Review of Psychology, 62, 103-134. http://dx.doi.org/10.1146/annurev-psych-120709-145406

[53] Ochsner, K.N. (2004) Current Directions in Social Cognitive Neuroscience. Current Opinion in Neurobiology, 14, 254258. http://dx.doi.org/10.1016/j.conb.2004.03.011

[54] Ziauddeen, H., Dibben, C., Kipps, C., Hodges, J.R. and McKenna, P.J. (2011) Negative Schizophrenic Symptoms and the Frontal Lobe Syndrome: One and the Same? European Archives of Psychiatry and Clinical Neuroscience, 261, 5967. http://dx.doi.org/10.1007/s00406-010-0133-y

[55] McEwen, B.S. (2012) Brain on Stress: How the Social Environment Gets under the Skin. Proceedings of the National Academy of Sciences of the United States of America, 109, 17180-17185. http://dx.doi.org/10.1073/pnas.1121254109

[56] Barrett, L., Henzi, P. and Rendall, D. (2007) Social Brains, Simple Minds: Does Social Complexity Really Require Cognitive Complexity? Philosophical Transactions of the Royal Society of London B: Biological Sciences, 29, 561-575. http://dx.doi.org/10.1098/rstb.2006.1995

[57] McEwen, B.S., Eiland, L., Hunter, R.G. and Miller, M.M. (2012) Stress and Anxiety: Structural Plasticity and Epigenetic Regulation as a Consequence of Stress. Neuropharmacology, 62, 3-12. http://dx.doi.org/10.1016/j.neuropharm.2011.07.014

[58] Millan, M.J., Agid, Y., Brüne, M., Bullmore, E.T., Carter, C.S., Clayton, N.S. and Young, L.J. (2012) Cognitive Dysfunction in Psychiatric Disorders: Characteristics, Causes and the Quest for Improved Therapy. Nature Review Drug Discovery, 11, 141-168. http://dx.doi.org/10.1038/nrd3628

[59] Beck, A.T. and Dozois, D.J. (2011) Cognitive Therapy: Current Status and Future Directions. Annual Review of Medicine, 62, 397-409. http://dx.doi.org/10.1146/annurev-med-052209-100032

[60] Snitz, B.E., McDonald, A.W. and Carter, C.S. (2006) Cognitive Deficits in Unaffected First Degree Relatives of Schizophrenia Patients: A Meta Analytic Review of Putative Endophenotypes. Schizophrenia Bulletin, 32, 179-194. http://dx.doi.org/10.1093/schbul/sbi048

[61] Disner, S.G., Beevers, D.G., Haigh, E.A. and Beck, A.T. (2011) Neural Mechanisms of the Cognitive Model of Depression. Nature Review Neuroscience, 12, 467-477. http://dx.doi.org/10.1038/nrn3027

[62] Clarke, T.K., Nymberg, C. and Schumann, G. (2012) Genetic and Environmental Determinants of Stress Responding. Alcohol Research, 24, 484-494.

[63] Curtis, A.L., Leiser, S.C., Snyder, K. and Valentino, R.J. (2012) Predator Stress Engages Corticotropin-Releasing Factor and Opioid Systems to Alter the Operating Mode of Locus Coeruleus Norepinephrine Neurons. Neuropharmacology, 62, 1737-1745. http://dx.doi.org/10.1016/j.neuropharm.2011.11.020

[64] Bangasser, D.A., Reyes, B.A.S., Piel, D., Garachh, V., Zhang, X.Y., Plona, Z.M. and Valentino, R.J. (2013) Increased Vulnerability of the Brain Norepinephrine System of Females to Corticotropin-Releasing Factor Overexpression. Molecular Psychiatry, 18, 166-173. http://dx.doi.org/10.1038/mp.2012.24

[65] Baumann, N. and Turpin, J.C. (2010) The Neurochemistry of Stress: An Overview. Neurochemistry Research, 35, 1875-1879. http://dx.doi.org/10.1007/s11064-010-0298-9 
[66] Kaufman, J., Plotsky, P.M., Nemeroff, C.B. and Charney, D.S. (2000) Effects of Early Adverse Experiences on Brain Structure and Function: Clinical Implications. Biological Psychiatry, 48, 778-790. http://dx.doi.org/10.1016/S0006-3223(00)00998-7

[67] Gayle, D.A., Beloosesky, R., Desai, M., Amidi, F., Nunez, S.E. and Ross, M.G. (2004) Maternal LPS Induces Cytokines in the Amniotic Fluid and Corticotrophin Releasing Hormone in the Fetal Rat Brain. American Journal of Physiology, 286, 1024-1029.

[68] Blackmore, S.J. and Robbins, T.W. (2012) Decision Making in the Adolescent Brain. Nature Neuroscience, 15, 11841191. http://dx.doi.org/10.1038/nn.3177

[69] Tanti, A. and Belzung, C. (2013) Neurogenesis along the Septo-Temporal Axis of the Hippocampus: Are Depression and the Action of Antidepressants Region-Specific? Neuroscience, 252, 234-252. http://dx.doi.org/10.1016/j.neuroscience.2013.08.017

[70] Heim, C. and Nemeroff, C.B. (2001) The Role of Childhood Trauma in the Neurobiology of Mood and Anxiety Disorders: Preclinical and Clinical Studies. Biological Psychiatry, 49, 1023-1039. http://dx.doi.org/10.1016/S0006-3223(01)01157-X

[71] Chen, Y., Brunson, K.L., Adelmann, G., Bender, R.A., Frotscher, M. and Baram, T.Z. (2004) Hippocampal Corticotrophin Releasing Hormone: Pre and Post Synaptic Location and Release by Stress. Neuroscience, 126, 533-540. http://dx.doi.org/10.1016/j.neuroscience.2004.03.036

[72] Mahgoub, M. and Monteggia, L.M. (2013) Epigenetics and Psychiatry. Neurotherapeutics, 10, 734-741. http://dx.doi.org/10.1007/s13311-013-0213-6

[73] Kas, M.J., Krishnan, V., Gould, T.D., Collier, D.A., Olivier, B., Lesch, K.P. and Castrén, E. (2011) Advances in Multidisciplinary and Cross-Species Approaches to Examine the Neurobiology of Psychiatric Disorders. European Neuropsychopharmacology, 21, 532-544. http://dx.doi.org/10.1016/j.euroneuro.2010.12.001

[74] Flint, J. and Munafo, M.R. (2007) The Endophenotype Concept in Psychiatric Genetics. Psychological Medicine, 37, 163-180. http://dx.doi.org/10.1017/S0033291706008750

[75] Abdolmaleky, H.M., Smith, C.L., Faraone, S.V., Shafa, R., Stone, W., Glatt, S.J. and Tsuang, M.T. (2004) Methylomics in Psychiatry: Modulation of Gene Environmental Factors May Be through DNA Methylation. American Journal of Medical Genetics, 127B, 51-59. http://dx.doi.org/10.1002/ajmg.b.20142

[76] Kato, T. (2009) Epigenomics in Psychiatry. Neuropsychobiology, 60, 2-4. http://dx.doi.org/10.1159/000234810

[77] Bredy, T.Y., Sun, Y.E. and Kobor, M.S. (2010) How the Epigenome Contributes to the Development of Psychiatric Disorders. Developmental Psychobiology, 52, 331-342. http://dx.doi.org/10.1002/dev.20424

[78] Wiers, C.E. (2012) Methylation and the Human Brain: Towards a New Discipline of Imaging Epigenetics. European Archives of Psychiatry and Clinical Neuroscience, 262, 271-273. http://dx.doi.org/10.1007/s00406-011-0261-z

[79] Fernando, S. (2012) Race and Culture Issues in Mental Health and Some Thoughts on Ethnic Identity. Counseling Psychology Quarterly, 25, 113-123. http://dx.doi.org/10.1080/09515070.2012.674299

[80] Pyari, T.T., Kutty, R.V. and Sarma, P.S. (2012) Risk Factors in Post Traumatic Stress Disorder Survivors in Kanyakumari District in Tamil Nadu. Indian Journal of Psychiatry, 54, 48-53. http://dx.doi.org/10.4103/0019-5545.94645

[81] Shrivastava, M.K., Sahoo, R.N., Ghotekar, L.H., Dutta, S., Danabalan, M., Dutta, T.K. and Das, A.K. (2004) Risk Factors Associated with Attempted Suicide: A Case Control Study. Indian Journal of Psychiatry, 46, 33-38. 
Scientific Research Publishing (SCIRP) is one of the largest Open Access journal publishers. It is currently publishing more than 200 open access, online, peer-reviewed journals covering a wide range of academic disciplines. SCIRP serves the worldwide academic communities and contributes to the progress and application of science with its publication.

Other selected journals from SCIRP are listed as below. Submit your manuscript to us via either submit@scirp.org or Online Submission Portal.
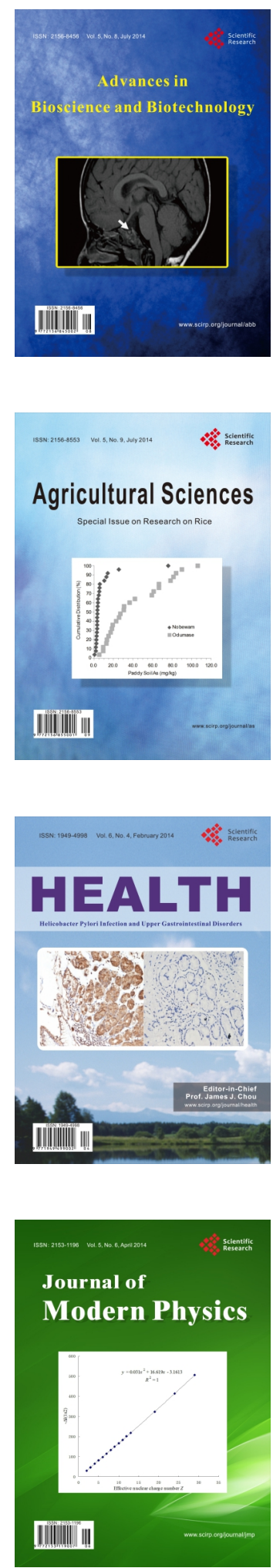
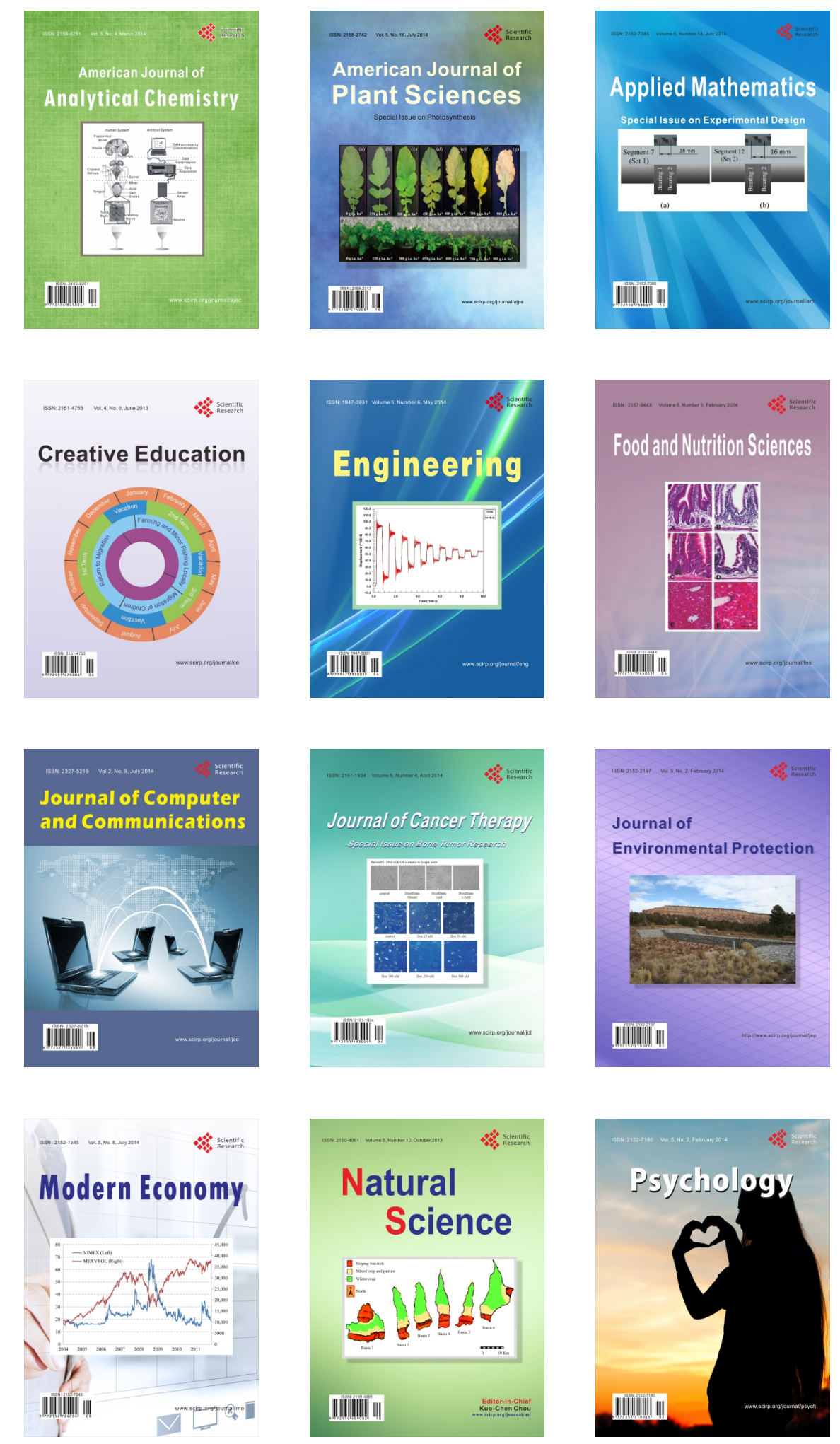